\title{
Effectiveness and safety of endoscopic radial incision and cutting for severe benign anastomotic stenosis after surgery for colorectal carcinoma: a three-case series $\square$
}

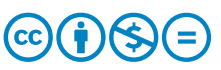

\author{
Authors \\ Naoki Asayama, Shinji Nagata, Kenjiro Shigita, Taiki Aoyama, Akira Fukumoto, Shinichi Mukai
}

Institution

Department of Gastroenterology, Hiroshima City Asa Citizens Hospital, Hiroshima, Japan

submitted 4.9.2017

accepted after revision 25.10.2017

Bibliography

DOI https://doi.org/10.1055/s-0043-124470 |

Endoscopy International Open 2018; 06: E335-E339

(c) Georg Thieme Verlag KG Stuttgart · New York ISSN 2364-3722

Corresponding author

Naoki Asayama, MD PhD, Department of Gastroenterology, Hiroshima City Asa Citizens Hospital, 2-1-1 Kabeminami, Asakita-ku, Hiroshima 731-0293, Japan

Phone: +81-82-815-5211

Fax: $+81-82-8141791$

asayama0502@hiroshima-u.ac.jp

\section{ABSTRACT}

Benign colonic anastomotic stenosis sometimes occurs after surgical resection and usually requires surgical or endoscopic dilation. Limited data are available on the effectiveness and safety of the endoscopic radial incision and cutting (RIC) method at sites other than the esophagus. The aim of this retrospective study was to investigate the effectiveness and safety of RIC dilation for severe benign anastomotic colonic stenosis. Subjects were 3 men (median age 72 years, range 65-76 years) who developed severe benign anastomotic stenosis after surgical resection for colorectal carcinoma and were subsequently treated by RIC dilation at Hiroshima City Asa Citizens Hospital between May 2014 and December 2016. Severe anastomotic stenosis was defined as a narrowed anastomosis through which a standard colonoscope could not be passed. The median interval from surgery to RIC was 21 months (range 9-29 months). RIC was successful in all 3 patients and reduced the severity of dyschezia postoperatively; 2 patients experienced improvement after a single RIC session and the other after 6 RIC sessions. No treatment-related adverse events or re-stenosis requiring repeat dilation was noted during a median follow-up of 27 months (range 8 37 months). Our findings indicate that the RIC technique can be applied safely and effectively to various sites in the colon, avoiding the need for reoperation.

\section{Introduction}

Benign anastomotic stenosis after colorectal resection is not an unusual event and occurs in $3-30 \%$ of patients [1]. The exact pathophysiology of such stricture is unknown, but use of a stapling device, postoperative anastomotic ischemia, anastomotic leak, pelvic infection, or postoperative radiation are believed to be contributing factors [1]. Traditionally, postoperative colonic stenosis has been managed surgically [1], but endoscopic treatment is now preferred over traditional surgery. Endoscopic balloon dilation (EBD) is presently the simplest therapeutic approach and has a good short-term success rate; however, in some patients, a fibrotic stricture is so inelastic that the balloon technique is ineffective or requires more than 1 dilation. In these patients, repeat procedures are necessary to achieve and maintain clinical success, but can markedly reduce quality of life and add considerably to the overall cost of treatment [1, 2]. The complications of EBD include bleeding and perforation, which occur in up to $5 \%$ of patients $[1,2]$.

The endoscopic radial incision and cutting (RIC) technique was recently developed to treat refractory stenosis and has been effective for treating refractory benign esophageal stricture $[3,4]$. To the best of our knowledge, there have been few reports on the application of RIC at sites other than the esophagus. Furthermore, few studies have evaluated the effectiveness and safety of RIC for severe benign anastomotic stenosis after surgery for colorectal carcinoma. Here, we evaluated the effectiveness and safety of endoscopic RIC therapy in patients with symptomatic severe anastomotic colonic stenosis. 


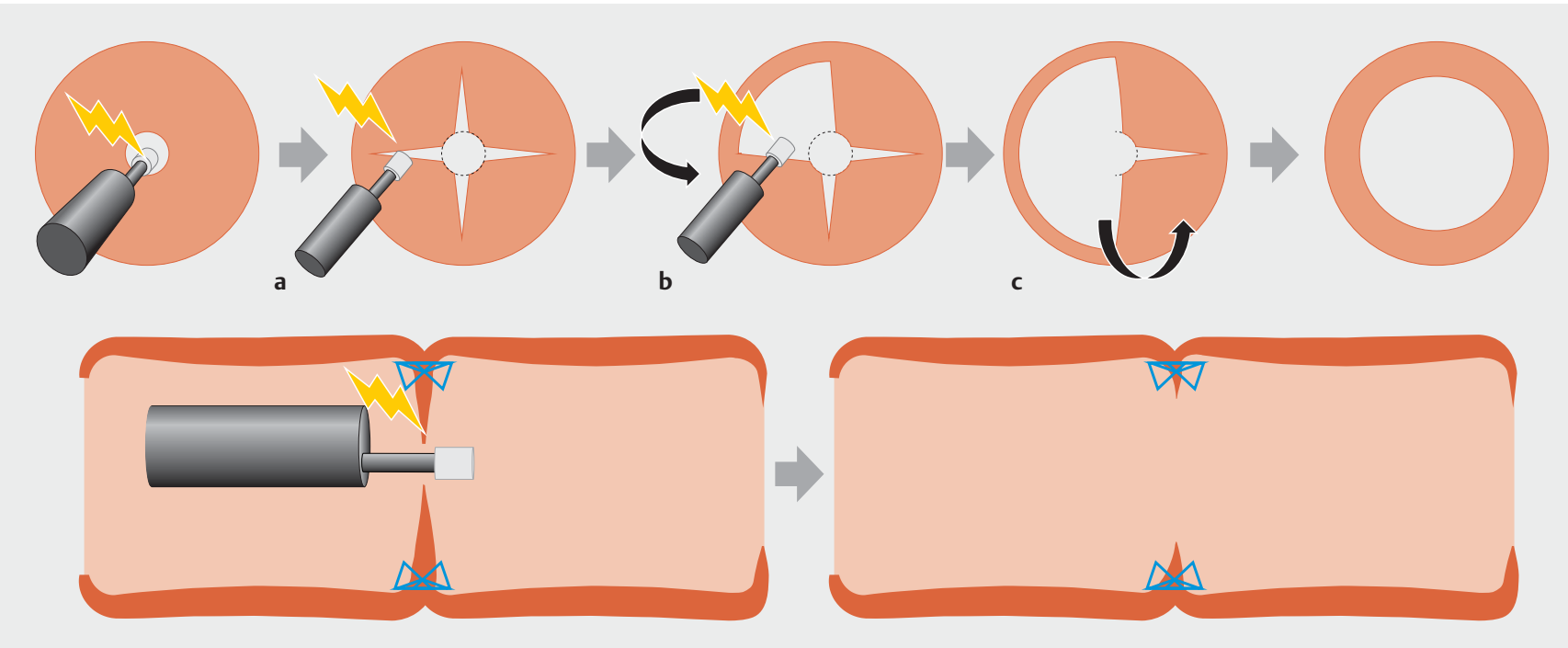

- Fig. 1 Schema showing the radial incision and cutting (RIC) method. a 4 or more incisions are made into the stenosed site using the ITknife nano. $\mathbf{b}$ The flaps formed by the incisions are removed using the blade. $\mathbf{c}$ The scar tissue is excised in an arc from the incision along the lumen. The staples serve as good landmarks for determining the depth of the cutting line.

\section{Case series}

3 consecutive patients were treated by RIC for severe benign anastomotic stenosis after surgery for colorectal carcinoma at Hiroshima City Asa Citizens Hospital between May 2014 and December 2016. Severe anastomotic stenosis was defined as (1) failure to pass a colonoscope measuring $11.7 \mathrm{~mm}$ in diameter (PCF Q260AZI; Olympus Medical Systems, Tokyo, Japan) through the stricture and (2) dyschezia-related problems such as constipation and/or abdominal distension. The stenosis was assessed radiologically as necessary. Written informed consent was obtained from all patients before RIC was performed.

The RIC procedure was performed as previously described ( $\triangleright$ Fig.1) [3,4] using the ITknife nano Electrosurgical Knife (Olympus Medical Systems). Briefly, the blade of the ITknife nano was first inserted into the stenosed area. 4 or more incisions were then made at the site using the knife. Next, the flaps formed by the incisions were removed. Finally, the scar tissue was excised in an arc from the incision along the lumen.

The patients received $7.5-15 \mathrm{mg}$ of pentazocine and 2$3 \mathrm{mg}$ of midazolam before RIC to minimize discomfort. The RIC procedure was performed by an endoscopist (SN) who had completed approximately 500 colorectal endoscopic submucosal dissection procedures between December 2006 and December 2016. The electrosurgical unit was set to Dry Cut mode (Effect 2, 30 W, VIO 300; Erbe Elektromedizin GmbH, Tübingen, Germany) for making the incisions at the stricture site and to Swift coagulation mode (Effect 2, $30 \mathrm{~W}$, VIO 300) for cutting the scar tissue. We considered treatment to have been successful if the anastomosis could be passed by the $11.7-\mathrm{mm}$ diameter colonoscope immediately after dilation.

Patient demographic and clinical characteristics are summarized in $>$ Table 1. All 3 patients were male, had a median age of 72 years, and had undergone laparoscopically assisted transverse colectomy or anterior resection as additional sur- gery after endoscopic resection for T1 carcinoma and sigmoid colectomy for advanced colorectal carcinoma. In all patients, the main clinical manifestation of the anastomotic stenosis before RIC was severe dyschezia. 1 of the patients also experienced abdominal pain.

The results of RIC are shown in $>$ Table 2. 1 patient had undergone 3 EBD procedures before RIC. The median interval from surgery to RIC was 21 months (range 9-29 months) and the median follow-up after RIC was 27 months (range 837 months). RIC was successful in all 3 patients and reduced the severity of dyschezia postoperatively according to patients' subjective verbal reports (\$ Fig. 2 and $>$ Fig. 3 ; \Video 1 ). 2 patients experienced improvement after a single RIC session and the third experienced improvement after 6 sessions. All 8 RIC sessions were performed on an inpatient basis with a median stay of 4 days (range $2-5$ days). The median RIC procedure time was 22 minutes (range 15-25 minutes). No severe adverse events, such as perforation, severe bleeding, high fever, or severe pain, were observed. No re-stenosis occurred and there was no need for additional dilation in any of the patients during follow-up.

\section{Discussion}

In this study, the severity of dyschezia caused by severe benign anastomotic stricture after surgery for colorectal carcinoma was dramatically reduced by RIC in all 3 patients and no severe adverse events occurred. EBD is the simplest therapeutic option for benign anastomotic stenosis, but it is associated with a high recurrence rate and with refractoriness in more than $20 \%$ of patients.

In contrast, RIC is less time-consuming and less expensive. EBD can open the lumen of the colon or rectum, but patency is not stably maintained because EBD tears the existing scar tis- 
- Table 1 Patient demographic and clinical characteristics.

\begin{tabular}{|c|c|c|c|c|c|c|c|c|}
\hline Patient & $\begin{array}{l}\text { Age, } \\
\text { years| } \\
\text { sex }\end{array}$ & $\begin{array}{l}\text { Comor- } \\
\text { bidity }\end{array}$ & $\begin{array}{l}\text { Tumor } \\
\text { location }\end{array}$ & $\begin{array}{l}\text { Treatment } \\
\text { approach }\end{array}$ & $\begin{array}{l}\text { Surgical } \\
\text { procedure }\end{array}$ & pTNM & $\begin{array}{l}\text { Postopera- } \\
\text { tive com- } \\
\text { plications }\end{array}$ & $\begin{array}{l}\text { Adjuvant } \\
\text { therapy }\end{array}$ \\
\hline 1 & $68 /$ Male & AAA & $\mathrm{T} / \mathrm{C}$ & EMR $\rightarrow$ operation & LAC & pT1bN0M0 & Ileus & None \\
\hline 2 & $65 /$ Male & DM, HTN & $S / C$ & Operation & Sigmoid colectomy & pT4aN1M0 & None & Chemotherapy \\
\hline 3 & 76/Male & HTN & $S / C$ & ESD $\rightarrow$ operation & LAR & pT1bN0M0 & None & None \\
\hline
\end{tabular}

AAA, abdominal aortic aneurysm; DM, diabetes mellitus; EMR, endoscopic mucosal resection; ESD, endoscopic submucosal dissection; HTN, hypertension; LAC, laparoscopy-assisted colectomy; LAR, laparoscopic anterior resection; S/C, sigmoid colon; T1b, submucosal invasion depth $\geq 1000 \mu \mathrm{m} ; \mathrm{T} / \mathrm{C}$, transverse colon.

- Table 2 Clinical outcomes of RIC.

\begin{tabular}{|c|c|c|c|c|c|c|c|c|}
\hline Patient & $\begin{array}{l}\text { Clinical mani- } \\
\text { festations }\end{array}$ & $\begin{array}{l}\text { Pretreat- } \\
\text { ment }\end{array}$ & $\begin{array}{l}\text { Interval from } \\
\text { surgery to RIC, } \\
\text { months }\end{array}$ & $\begin{array}{l}\text { RIC ses- } \\
\text { sions }(n)\end{array}$ & $\begin{array}{l}\text { Operation } \\
\text { time, min }\end{array}$ & $\begin{array}{l}\text { Major compli- } \\
\text { cations }\end{array}$ & $\begin{array}{l}\text { Hospital } \\
\text { stay, } \\
\text { days }\end{array}$ & $\begin{array}{l}\text { Follow-up } \\
\text { after RIC, } \\
\text { months }\end{array}$ \\
\hline 1 & $\begin{array}{l}\text { Abdominal pain, } \\
\text { severe dyschezia }\end{array}$ & $\mathrm{BD}$ & 29 & 6 & $15-25$ & None & $3-5$ & 34 \\
\hline 2 & Severe dyschezia & None & 9 & 1 & 20 & None & 2 & 5 \\
\hline 3 & Severe dyschezia & None & 13 & 1 & 15 & None & 2 & 16 \\
\hline Median & & & 21 & 3.5 & 22 & & 4 & 25 \\
\hline
\end{tabular}

sue and repeated traumatic dilations can increase mucosal scarring [5]. The scar tissue, which is a by-product of repeated $E B D$, remains after the dilation procedure and results in re-stenosis after wound healing. Therefore, the superiority of the RIC method may lie in its usefulness for treating refractory stenosis by directly removing the fibrotic tissue caused by repeated balloon dilations. This ability to remove the fibrotic tissue directly may contribute to the effectiveness of RIC and resolve the refractory anastomotic stricture. Of note, we used the ITknife nano to perform all RIC procedures in this series; the insulated tip avoids inadvertent injury to the muscle layer, and the smaller insulated tip and small disc blade have the advantage that fixing of the tip to the scar tissue allows for stable dissection of the fibrotic tissues.

Few studies have evaluated the efficacy and safety of RIC for severe benign anastomotic stenosis after surgery for colorectal carcinoma. Osera et al. [6] reported that RIC was successful in 5 of 7 patients with such stenosis after surgery for lower rectal carcinoma. In the 2 patients for whom RIC was unsuccessful, the procedure was deemed a failure after 4 RIC sessions in 1 patient and 6 in the other. Therefore, 16 RIC sessions in total were performed in the 7 patients. Harada et al. [7] reported that 4 sessions of RIC were effective in 3 patients with rectal anastomotic strictures refractory to conventional EBD and repeated mechanical or finger-bougie dilation. In a case report by Kawaguti et al. [8], RIC was suggested to be feasible, effective, and safe for the treatment of severe anastomotic stenosis after surgery for lower rectal carcinoma. In our patients, the stenoses were located at various sites in the colon, and RIC provided re- lief with a low complication rate, thereby avoiding the need for reoperation.

1 of our 3 patients experienced improvement after 6 RIC sessions. This patient was admitted to our hospital twice because of ileus after laparoscopic colectomy. Postoperative anastomotic ischemia and leakage were considered to have contributed to the admission for ileus, and the refractoriness of the anastomotic stenosis was attributed to technical difficulties associated with the RIC procedure.

To our knowledge, this is the first report on the use of RIC for treating severe benign anastomotic stenosis at various sites in the colon. There were no severe adverse events and no reoperations were needed.

There are no clear criteria with regard to the indications for RIC, and individual patients are presently accepted after consultation between the gastroenterologists, surgeons, and pathologists. The contraindications are as follows: the blade of an ITknife nano cannot pass through the stenosis because it is too narrow; the scar tissue associated with the stenosis is so firm after electrocautery that an incision using an ITknife nano cannot be performed; the axial direction of the intestine is not the same between the anal side and the oral side; and the stenosis is too long for the procedure to be technically feasible.

The main difficulty encountered when using an ITknife nano to excise scar tissue from an anastomotic site is that the scar adheres tightly to the intestinal wall. Furthermore, it is impossible to inject material, including sodium hyaluronate, into an anastomotic stricture site when severe fibrosis is present. Therefore, RIC needs to be performed carefully without any injection in the treatment region. 

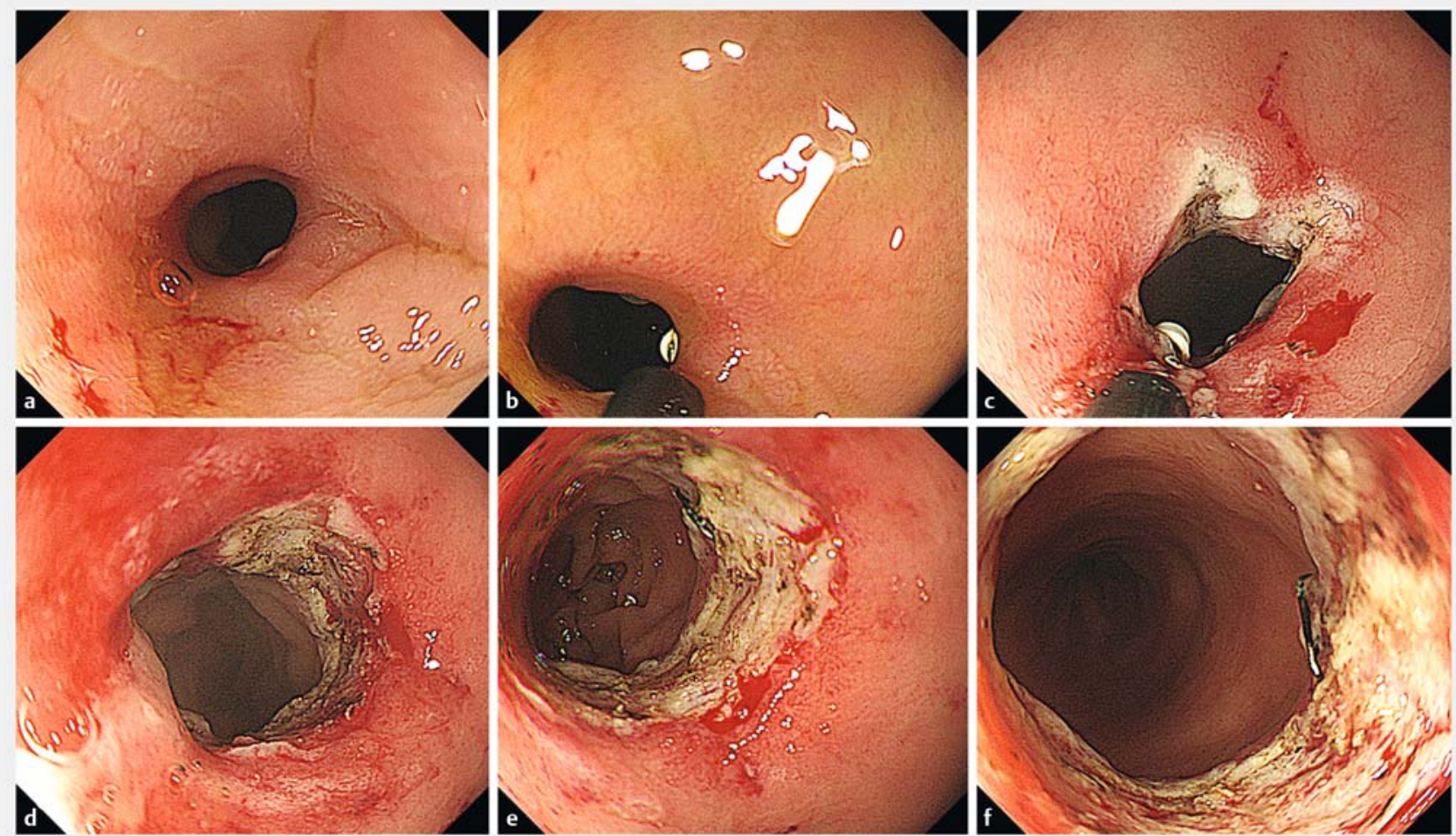

- Fig. 2 Details of the radial incision and cutting (RIC) procedure performed in patient 2. a, b The blade of the ITknife nano is inserted into the stenosed area. c At least 4 incisions are made into the stenosed site using the knife. $\mathbf{d}$, $\mathbf{e}$ The flaps formed by the incisions are removed using the blade of the knife, and the scar tissue excised in an arc from the incision along the lumen. $f$ Treatment is considered successful because the colonoscope could easily pass through the anastomosis.
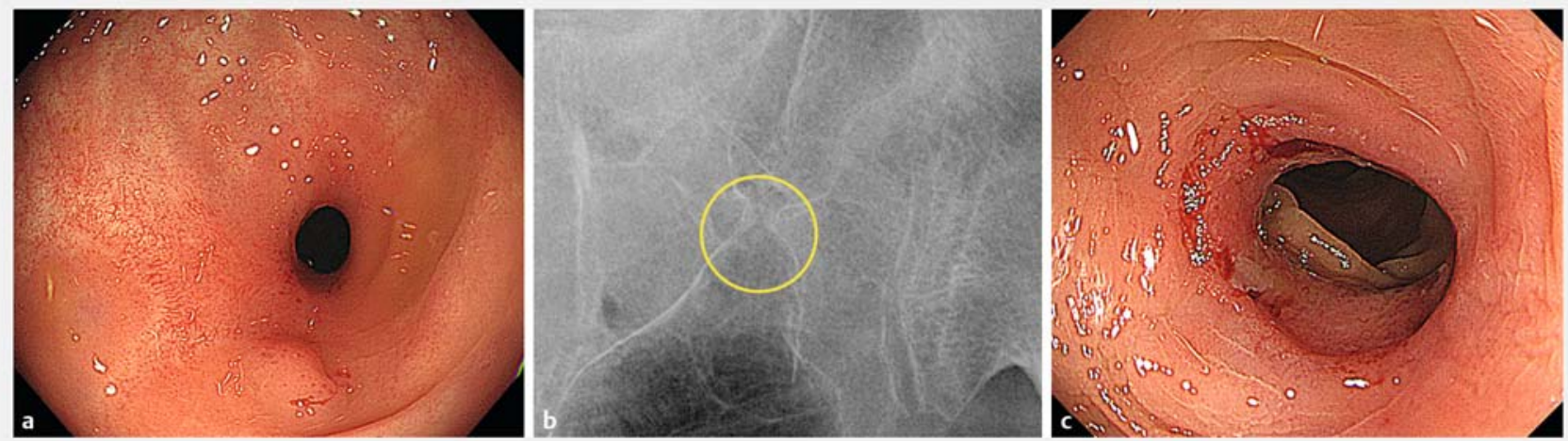

- Fig.3 Representative images from patient 2. a Colonoscopy performed before the radial incision and cutting (RIC) procedure shows severe anastomotic stenosis 6 months after sigmoid colectomy for colorectal carcinoma. b A barium enema shows the stricture at the level of the anastomosis in the sigmoid colon. c 5 months after RIC, there is a remarkable improvement in the stenosis and dyschezia.

Several precautions are necessary to prevent perforation: the oral side of the intestine should be assessed radiologically if necessary before an incision is made using the ITknife nano; the patient should not be sedated too deeply (so that any adverse events that occur can be detected early); the blade of the ITknife nano should be positioned parallel to the lumen directly over the scar tissue; and incisions should be made carefully with the knife perpendicular to the lumen.
It is very important that the amount of scar tissue incised does not exceed the length of the stenosed segment on the oral side because the risk of perforation increases when the stenosis is cut deeply in 1 session. Staples serve as good landmarks for determining the depth of the cutting line. If the staples are exposed, it is important not to cut the scar tissue any further.

Although several studies have demonstrated the feasibility of stent insertion for refractory anastomotic colorectal stric- 


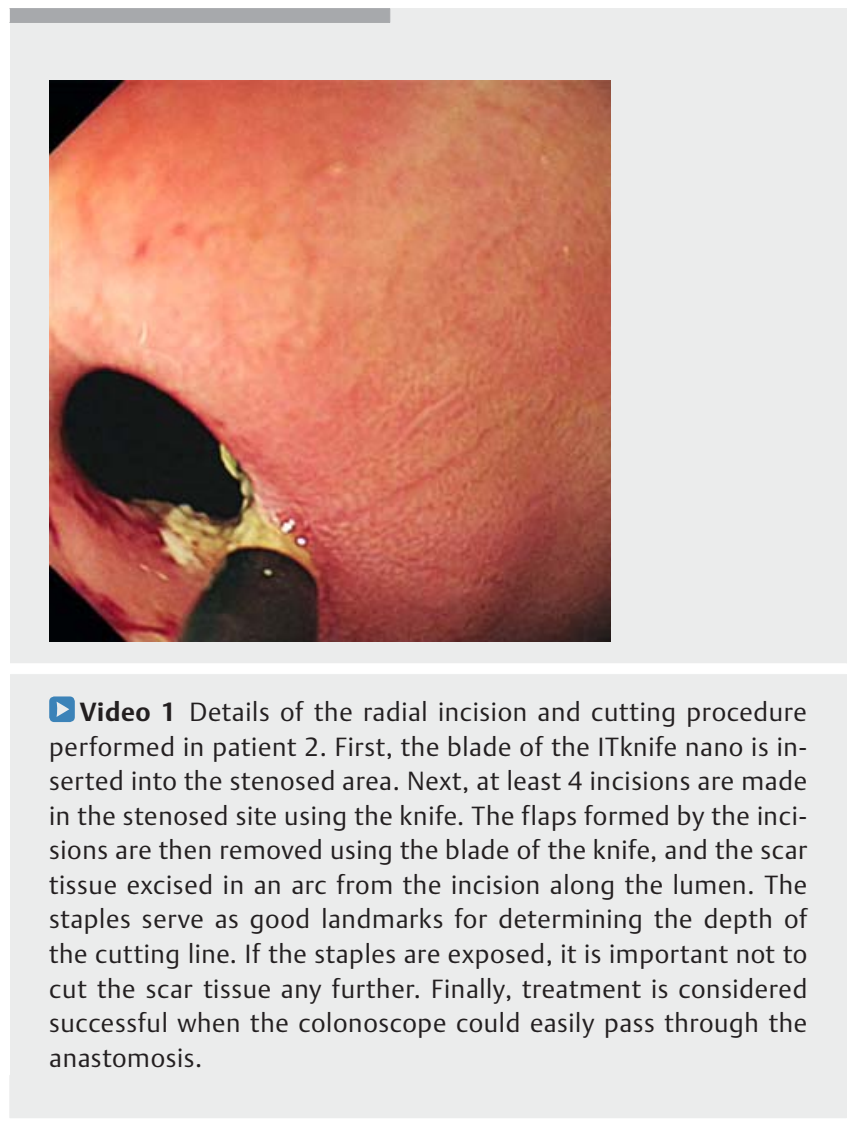

ture, this procedure is technically difficult because of stent migration, bleeding, or even perforation. A stent might also need to be removed after placement because of foreign body reaction $[9,10]$. Moreover, stent insertion for refractory anastomotic colorectal stenosis is not covered by the Japanese health insurance system.

Our findings indicate that dilation by RIC is feasible, effective, and safe for the treatment of severe anastomotic stenosis after surgery for colorectal carcinoma. The effectiveness of RIC combined with steroid injection is still controversial and needs further study. RIC is performed at only a few institutions at present, so limited clinical data are available. Large-scale, mul- ticenter, prospective investigations are warranted to evaluate the long-term outcomes of RIC.

\section{Competing interests}

None

\section{References}

[1] Garcea G, Sutton CD, Lloyd TD et al. Management of benign rectal strictures: a review of present therapeutic procedures. Dis Colon Rectum 2003; 46: 1451 - 1460

[2] Suchan KL, Muldner A, Manegold BC. Endoscopic treatment of postoperative colorectal anastomotic strictures. Surg Endosc 2003; 17: $1110-1113$

[3] Muto M, Ezoe Y, Yano T et al. Usefulness of endoscopic radial incision and cutting method for refractory esophagogastric anastomotic stricture (with video). Gastrointest Endosc 2012; 75: 965 - 972

[4] Yano T, Yoda Y, Satake $\mathrm{H}$ et al. Radial incision and cutting method for refractory stricture after nonsurgical treatment of esophageal cancer. Endoscopy 2014; 45: 316-319

[5] Cheng YS, Li MH, Yang RJ et al. Restenosis following balloon dilation of benign esophageal stenosis. World J Gastroenterol 2003; 9: $2605-$ 2608

[6] Osera S, Ikematsu H, Odagaki T et al. Efficacy and safety of endoscopic radial incision and cutting for benign severe anastomotic stricture after surgery for lower rectal cancer (with video). Gastrointest Endosc 2015; 81: $770-773$

[7] Harada K, Kawano S, Hiraoka S et al. Endoscopic radial incision and cutting method for refractory stricture of a rectal anastomosis after surgery. Endoscopy 2015; 47: (Suppl. 01): E552-553

[8] Kawaguti FS, Martins BC, Nahas CS et al. Endoscopic radial incision and cutting procedure for a colorectal anastomotic stricture. Gastrointest Endosc 2015; 82: 408 - 409

[9] Keränen I, Lepistö A, Udd M et al. Outcome of patients after endoluminal stent placement for benign colorectal obstruction. Scand J Gastroenterol 2010; 45: 725-731

[10] Majumder S, Buttar NS, Gostout C et al. Lumen-apposing covered self-expanding metal stent for management of benign gastrointestinal strictures. Endosc Int Open 2016; 4: E96-E101 